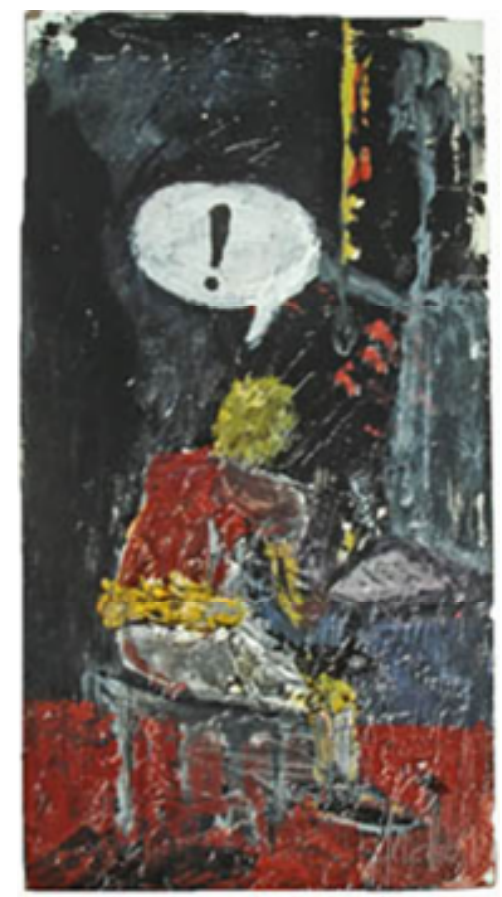

\title{
Histórias em quadrinhos: um suporte a mais na formação de leitores
}

\section{Lavínia Resende Passos \\ Maria das Graças Fernandes Nogueira}

Lavínia Resende Passos é graduanda em Letras com Formação Complementar em Comunicação Social. É membro do Programa de Ensino, Pesquisa e Extensão A tela e o texto desde 2005, onde desenvolve pesquisa na área de literatura e cinema, subcoordena o setor de Cursos e Oficinas e, como tal, participa do Projeto Escola Integrada (parceria UFMG/PROEX e $S M E D / B H)$, com a oficina "Quadrinhos: uma abordagem para além da diversão".

Maria das Graças Fernandes Nogueira é professora de Língua Portuguesa e Literatura Brasileira. Mestre em Teoria da Literatura, FALE/UFMG. Coordenadora do setor de Cursos e Oficinas do Programa A tela e o texto. Coordenadora das oficinas do Programa Escola Integrada (PROEX/UFMG e SMED/PBH). 


\section{Resumo}

Este artigo tem como objetivo mostrar como as histórias em quadrinhos, ao serem utilizadas no aprendizado do Português, na adaptação de obras literárias e como uma preparação para a leitura dessas, são importantes na formação de leitores.

Palavras-chave: histórias em quadrinhos, literatura, formação de leitores.

Por leitura, segundo Cafieiro, (1) entende-se uma atividade ou um processo cognitivo de construção de sentidos realizado por sujeitos sociais inseridos num tempo histórico, numa dada cultura. Percebe-se, com essa definição, que a leitura vai muito além da decifração de códigos linguísticos. Sua plena realização consiste na capacidade de o sujeito entender o que lê e levar esse aprendizado a seu mundo, facilitando sua interação com o mesmo.

Porém, para se ter a compreensão completa de um texto é importante que o leitor conheça seus tipos, seus modos e suas formas. O texto, por si só, já diz como deve ser lido. Os comportamentos dos leitores vão ser diferentes de acordo com o tipo de leitura, de acordo com o pacto que se forma entre autor e leitor. Regina Zilmerman, em Tipos de texto, modos de leitura nos fala de um leitor "múltiplo, que é, no fundo, um único sujeito que, camaleonicamente, se transforma diante de desafios plurais que cada texto lhe impõe". Um texto literário, por sua beleza estética, por sua forma conotativa, pela emoção que carrega, trava com seu leitor um pacto muito maior do que qualquer outra forma de texto.

Assim um texto não se resume à soma das palavras que o compõem. Deve-se valorizar a tipologia de cada texto e suas especificidades, as experiências pessoais dos alunos e seus conhecimentos de mundo associados à sua bagagem lingüística como léxico, regras gramaticais, particularidades discursivas - para que as idéias do texto sejam compreendidas por cada aprendiz .

Nesse caso, leitura e literatura dificilmente são vistas como autônomas, pois atuam como instrumento uma da outra. As propostas de ensino da língua materna propõem que a leitura seja a base para esse estudo devido às vantagens trazidas em relação à linguagem. Para o ensino e o aprendizado, seja do português ou de qualquer língua estrangeira, os textos literários são materiais muito ricos, pois não se limitam a aspectos estruturais da língua. Tais textos também difundem a cultura de um povo. Além disso, favorecem o desenvolvimento de 
uma visão crítica nos alunos devido a elementos característicos da literatura, como a subjetividade e a ambigüidade que estimulam discussões e permitem diversas interpretações para o texto. São fundamentais, portanto, por proporcionarem uma gama de alternativas de trabalho ao professor e despertarem o interesse dos alunos, desde que sejam bem selecionados, enquanto desenvolvem naturalmente a compreensão leitora, a produção oral e escrita. O uso do texto literário em situações de aprendizagem da Língua Portuguesa (aulas de cursos regulares, oficinas etc.) é um estímulo lingüístico e cultural para os alunos, além de apresentar uma finalidade comunicativa. A forma e o conteúdo do texto literário são elementos básicos para seu estudo. A primeira trata da estrutura da obra, dos recursos expressivos, da sintaxe e do léxico e o segundo se centra nas temáticas aludidas e nos elementos culturais ali presentes. Esses dados favorecem a aproximação cultural, ao mesmo tempo em que desenvolvem a riqueza da interlíngua. Dessa maneira, o aluno adquire autonomia, amplia o léxico, exercita a habilidade de síntese e adquire o domínio da língua em diferentes situações.

Assim, quando a literatura exige de seu leitor um grau maior de envolvimento, quando faz com que ele consiga identificar a forma do que está lendo, o estilo, as emoções e os sentimentos expressos pelo autor e, principalmente, contrastar sua opinião com a do texto, acredita-se que ela, a literatura, esteja cumprindo seu papel enquanto formadora de leitores.

E se um texto literário é capaz de ajudar na formação de leitores, o mesmo efeito pode ser causado por suas releituras por meio da charge, do cinema e da tv, por exemplo. Todas essas leituras possíveis na contemporaneidade trazem em si a inovação do suporte, mas muitas vezes vão buscar na literatura o conteúdo. Hoje em dia, os filmes adaptados da literatura, assim como as novelas e as minisséries de TV, favorecem a vendagem e a leitura das obras que os inspiraram.

Nas histórias em quadrinhos, a situação não é diferente. Embora elas tenham personagens próprios, muitas vezes eles interpretam personagens famosos da história da literatura, como é o caso das histórias de Maurício de Souza, cuja Mônica já foi Julieta, do clássico Romeu e Julieta, assim como Magali já foi A bela adormecida(2). É comum também as historinhas trazerem a moral da história e inevitavelmente, adaptarem fábulas das mais diversas regiões. Mais recentemente, personagens da literatura brasileira foram transformados em personagens de história em quadrinho. A editora Escala Educacional lançou a coleção Literatura Brasileira em quadrinhos, onde clássicos como o cortiço e 0 alienista são apresentados na versão HQs(3). A utilização desses recursos como um incentivo à leitura, como suporte à literatura e, 
conseqüentemente, como auxílio à formação de leitores, é uma proposta pertinente.

No entanto, a aplicação de histórias em quadrinhos nas salas de aula, com esses objetivos, foi algo recusado durante muito tempo por pais e professores. Por não conhecerem bem o assunto, acreditavam que as HQs eram objetos puramente comerciais, dedicados apenas ao lazer e à distração, sem utilidade para o ensino. Com o tempo, esses argumentos não se sustentaram e atualmente a LDB (Lei de Diretrizes e Bases) e os PCNs (Parâmetros Curriculares Nacionais) incentivam seu uso em sala de aula.

Vários são os motivos que fazem com que as histórias em quadrinhos sejam auxiliares no processo de formação de leitores. O primeiro deles é a forma como se apresentam palavra e imagem, ambas como instância de enunciação. A integração das duas linguagens representa, ao mesmo tempo, os personagens e as ações. Além das palavras "presas" aos balões, característica marcante das HQs, há também os signos convencionais: o icônico (um coração sobre a cabeça para representar a paixão, por exemplo), e o gráfico (tamanho e forma das letras, onomatopéias). A imagem, no caso das HQs se faz dominante, uma vez que várias histórias são contadas sem o suporte do texto verbal. O entendimento do relato desenvolvese pela leitura icônica. Nesse caso, é imprescindível a formação para a leitura de imagens, que atualmente é uma das formas mais corriqueiras de se produzir comunicação e obter informação. No entanto, essa leitura é desprezada por muitos professores e leitores em geral que têm como modelo de leitura a imagem universal do texto verbal:

Essa imagem tradicional da leitura, apoiada exclusivamente no texto escrito erudito, ainda persiste na escola brasileira e expressa uma concepção elitista da literatura. A escola, apesar de sua preocupação fundamental com o ensino da leitura e da escrita, esquece-se de códigos que começaram a tomar corpo a partir da segunda metade do século XIX, como a fotografia, o cinema e as HQs ( 4 ).

O estudo das imagens deve ser levado em conta na formação de leitores, uma vez que estamos inseridos numa sociedade "marcada pela iconização da realidade."(5). A leitura da imagem é essencial pois se tem nela a representação máxima dessa realidade; é uma nova forma de ver, de ler, além de se desenvolver habilidades de compreensão estética. Nesse sentido, as HQs cumprem seu papel ao trabalharem com expressões e gestos dos personagens, o uso de sinais icônicos e gráficos, os cenários e o sentido das imagens em relação ao texto. 
Outro aspecto a ser levado em conta é que a maioria das histórias trazer temas cotidianos, o que permite ao leitor se reconhecer no personagem e verificar situações semelhantes às de sua própria vida. Também pode-se explorar a situação oposta, quando se têm as histórias de super-heróis, seres com poderes fantásticos, que habitam lugares imaginários, formas essas que despertam o interesse e a criatividade. Nos dois contextos, o leitor é levado a buscar experiências em seu conhecimento de mundo para preencher as lacunas existentes entre uma cena e outra, interagindo com o texto.

A figura do narrador é outro ponto a ser citado. Enquanto nas narrativas literárias sua intervenção se dá de forma verbal e linear, nas HQs elas podem aparecer como vinhetas, na parte externa dos quadrinhos; o próprio narrador, que estava de fora da história, pode passar a interferir nela, mesmo quando narra em terceira pessoa. Todo o processo de coesão existente nas HQs contribui para que essas interferências não prejudiquem o entendimento. Esse processo se dá tanto pela articulação dos quadros, como pela articulação interna das etapas do enredo e, claro, pela visualidade da página. As cenas escolhidas para serem desenhadas são aquelas que mais importância têm na compreensão da narrativa. "A fluidez da narrativa depende, ainda, de componentes como o título, o enredo e outros elementos verbais que podem assumir o caráter de ícones, índices ou símbolos."(6).

Muitas vezes, vemos as figuras de linguagem aparecerem nas histórias em quadrinhos. A metalinguagem, por exemplo, é evidenciada quando um personagem, insatisfeito com determinada situação, conversa com o desenhista/roteirista e, a partir de então, podemos ver a imagem de uma borracha aparecer, atuar, sendo a situação redesenhada/reescrita. A metáfora também está presente na forma visual: quando alguém cai ou tromba com algo, a sensação de tontura pode ser expressa pelo desenhos de estrelas ou passarinhos girando sobre a cabeça do personagem. Outra figura utilizada é o eufemismos, representaodo por ícones como bombas, caveiras, raios, cobras etc.

Podemos perceber, pelos motivos acima mencionados, que mesmo quando o texto das HQs não é uma releitura, as histórias trazem vários elementos da literatura para sua narrativa, sendo então válidas para o estudo da linguagem. Os leitores, estando adaptados a esse gênero, podem passar a ler as HQs adaptadas das obras literárias, como uma forma de preparação para a leitura do texto em livro.

"A literatura, por ser uma das formas de aproximação da diversidade cultural de nosso mundo, constitui uma ferramenta útil para familiarizar os alunos com outros mundos e ampliar seus horizontes culturais." Sendo assim, os primeiros contatos 
com a literatura "podem ser efetuados de uma forma mais prazerosa, a partir de HQs, ao mesmo tempo que prepararão o caminho para uma posterior leitura desses gêneros nas versões de livros"(7).

A leitura, portanto, constitui-se como um processo interativo entre 0 autor, 0 mundo e o aluno. Por isso, a leitura interativa é o modelo mais apropriado para a formação incial de leitores, visto que há um processo de intercâmbio entre eles e o texto por meio da reunião de informações imagéticas e simbólicas. Esse processo torna a atividade de ler uma tarefa de mão dupla, pois depende tanto dos traços lingüísticos do texto como dos sucessos vividos pelo aluno.

Por tudo o que já foi dito, conclui-se que essas habilidades são despertadas no leitor seja quando ele lê uma obra literária, seja quando lê uma história em quadrinhos. Sendo assim, pode-se dizer que as HQs e a literatura, associadas em um processo de apreensão textual, são importantes na formação de leitores.

\section{Resumen}

Este artículo tiene por objetivo enseñar cómo los tebeos, al ser utilizados en el aprendizaje del portugués, en la adaptación de obras literarias y en la preparación de su lectura son importantes en la formación de lectores.

Palabras clave: tebeos, literatura, formación de lectores.

\section{Notas}

(1) CAFIEIRO, 2005. p. 17

(2) Várias histórias adaptadas dos clássicos da literatura podem ser lidas no site: www.monica.com.br. A reprodução das mesmas não pôde ser feita aqui em respeito às normas do site. É importante destacar que, a partir da década de 80, a equipe de Maurício de Souza incorporou as tecnologias da comunicação e passou a disponibilizar suas histórias em outros suportes: em almanaques, livros, filmes e pela Internet. No site, acessando o link quadrinhos, o leitor tem acesso a um calendário com as tirinhas e histórias semanais, ou mesmo as histórias escritas em séries, que em sua maioria, são as que revivem os clássicos literários. Surge, então, uma nova possibilidade de leitura, os quadrinhos nas telas do computador.

(3) Para maiores informações:

http://www.escalaeducacional.com.br/paradidalitbras.asp.

(4) SANTOS, 2002. p.136.

(5) SANTOS, 2002. p.136. 
(6) SANTOS, 2002. p.117.

(7) SANTOS, 2002. p.138.

\section{Bibliografia}

BENCINI, Roberta. Todas as leituras. Revista Nova escola. Editora Nova Abril, agosto/2006. p. 1 a 39.

CAFIEIRO, Delaine. Leitura como processo: caderno do formador. Belo Horizonte: CEALE/FaE/UFMG, 2005. Coleção Alfabetização e Letramento.

CoscARelli, Carla Viana. Livro de receita do professor de Português. Atividades para a sala de aula. $2^{\circ}$ ed. Belo Horizonte: Autêntica, 2003.

KOCH, Ingedore Vilaça e ELIAS, Vanda Maria. Ler e compreender: os sentidos do texto. São Paulo: Contexto, 2005.

PAULINO, Graça; WALTY, Ivete; FONSECA, Maria N.; CURY, Maria Z. Tipos de texto, modos de leitura. Belo Horizonte: Formato Editorial, 2001.

RAMA, Angela e VERGUEIRO, Waldomiro. (org.) Como usar os quadrinhos em sala de aula. $3^{\circ}$ ed. São Paulo: Contexto, 2006.

SANTos, Clarisse Barbosa dos. Quadrinhos e Chico Bento um texto caleidoscópico. Universidade Federal de Minas Gerais, 2002 (PEREIRA, Maria Antonieta,). 2002 enc. Dissertação (mestrado) - Universidade Federal de Minas Gerais.

VIEIRA, Marli. Por trás das letras. In: Revista Aprende Brasil, v.2, n.7, outubro/novembro 2006. p. 12 a 14 . 